\title{
Seasonal variation of brain size in a freshwater top predator
}

\author{
Evan Versteeg ${ }^{1}$, Timothy Fernandes ${ }^{1}$, Matthew Guzzo ${ }^{1}$, Frederic Laberge ${ }^{2}$, Trevor Middel ${ }^{3}$, \\ Mark Ridgway ${ }^{3}$, and Bailey McMeans ${ }^{1}$ \\ ${ }^{1}$ University of Toronto - Mississauga \\ ${ }^{2}$ University of Guelph \\ ${ }^{3}$ Ontario Ministry of Natural Resources and Forestry
}

June 8, 2021

\begin{abstract}
1. Teleost fishes occupy a range of ecosystem and habitat types subject to large seasonal fluctuations. Temperate fishes in particular, survive large shifts in temperature, light availability, and access to certain habitats across seasons. Yet, there is limited understanding of how behavioral responses to a seasonally shifting environment might shape, or be shaped by, the nervous system. 2. Here we quantified variation in relative brain size and the size of five externally visible brain regions in a freshwater top predator, lake trout (Salvelinus namaycush), across six consecutive seasons in two different lakes. Acoustic telemetry data from one of our study lakes was collected during the study period from a different subset of individuals and used to infer relationships between brain size and seasonal behaviors (habitat use and movement rate). 3. Our results indicated that lake trout relative brain size was larger in the fall and winter compared to the spring and summer in both lakes. Larger brains coincided with increased use of nearshore lake habitats and increased horizontal movement rates by lake trout in the fall and winter based on acoustic telemetry. The telencephalon followed the same pattern as whole brain size, while the other brain regions (cerebellum, optic tectum, olfactory bulbs, hypothalamus) were only smaller in the spring. 4. Seasonal shifts in total brain size might reflect greater underlying changes in the size of the telencephalon. These findings provide evidence that flexibility in brain size could underpin shifts in behavior which could subserve functions associated with differential habitat use during cold and warm seasons and allow fish to succeed in seasonally variable temperate environments.
\end{abstract}

\section{Seasonal variation of brain size in a freshwater top predator}

\section{Abstract}

1. Teleost fishes occupy a range of ecosystem and habitat types subject to large seasonal fluctuations. Temperate fishes in particular, survive large shifts in temperature, light availability, and access to certain habitats across seasons. Yet, there is limited understanding of how behavioral responses to a seasonally shifting environment might shape, or be shaped by, the nervous system.

2. Here we quantified variation in relative brain size and the size of five externally visible brain regions in a freshwater top predator, lake trout (Salvelinus namaycush), across six consecutive seasons in two different lakes. Acoustic telemetry data from one of our study lakes was collected during the study period from a different subset of individuals and used to infer relationships between brain size and seasonal behaviors (habitat use and movement rate).

3. Our results indicated that lake trout relative brain size was larger in the fall and winter compared to the spring and summer in both lakes. Larger brains coincided with increased use of nearshore lake habitats and increased horizontal movement rates by lake trout in the fall and winter based on acoustic telemetry. The telencephalon followed the same pattern as whole brain size, while the other brain regions (cerebellum, optic tectum, olfactory bulbs, hypothalamus) were only smaller in the spring. 
4. Seasonal shifts in total brain size might reflect greater underlying changes in the size of the telencephalon. These findings provide evidence that flexibility in brain size could underpin shifts in behavior which could subserve functions associated with differential habitat use during cold and warm seasons and allow fish to succeed in seasonally variable temperate environments.

\section{Keywords}

Acoustic telemetry, behavior, brain regions, brain size, habitat complexity, lake trout, phenotypic flexibility, seasonality.

\section{Introduction}

Teleost fishes exhibit exceptional flexibility in their behavioral and physiological responses to changing environments, which has allowed them to colonize an impressive number of habitats at different latitudes (Dill 1983, Armstrong and Bond 2013). Previous work on freshwater fish has highlighted the need to better document and resolve the role of neural flexibility in underpinning life history strategies and ecology among different species and populations (Gonda et al. 2013). Fish often exhibit large variation in the proportional size of their brain regions in association with ecological and sensory specialization (Kotrschal et al. 1998, Gonzalez-Voyer and Kolm 2010). There is, however, a growing body of experimental literature suggesting that novel environments can influence fish brain size within the span of a few weeks or months (Park et al. 2012, Herczeg et al. 2015, Turschwell and White 2016, Fong et al. 2019, Závorka et al. 2020). If fish are capable of rapidly adjusting their brain size to cope with new environments, then perhaps fish can exhibit changes in brain size that allow them to succeed in the face of seasonal and interannual changes in natural environments.

Seasonality in temperate lake ecosystems generates dramatic declines in temperature and light levels during the late fall and winter due to shifting daylight cycles and ice/snow cover. Species time the phenology of many key life history events (e.g. Salvelinus namaycushreproduction; Martin 1957) and activity patterns with these seasonal cycles. Some species, for example, suppress their activity in response to winter conditions and wait to reproduce until the spring, while others reproduce in the fall and remain active all winter (Shuter et al. 2012). In either case, predictable seasonal habitat shifts are commonplace among temperate fish species (e.g. to reach spawning sites or overwintering areas or to access prey; Hanson et al. 2008, Shuter et al. 2012). It is possible then, that coupled seasonal shifts in abiotic conditions and fish behavior could increase cognitive demands during particular seasons.

Brain and brain region size is correlated with performance in cognitively demanding tasks (Kotrschal et al. 2013, Buechel et al. 2018) and with variation in neuron numbers (Marhounová et al. 2019). As such, brain size variation is generally conceived as relating to variation in cognitive demands (i.e. sensory, motor, and integrative functions). To date, only a single study has explored seasonal variation in the size of one brain region (the telencephalon) in a wild fish, the round goby (Neogobius melanostomus ). This study found larger telencephalon sizes during the reproductive season, which was associated with the increased spatial processing demands of mating (McCallum et al. 2014). It is still unknown however, whether whole brain size is seasonally flexible in fishes, or if the size of individual brain regions can change independently of one another across seasons.

Here, we investigated the seasonal variability in total brain mass and individual region volumes (Figure. 1) of lake trout (Salvelinus namaycush) from two lakes in Ontario, Canada. We first hypothesized that seasonal changes in cognitive demands would drive changes in lake trout brain size over a seasonal timescale. Second, we hypothesized that any changes in overall brain size were either the result of: a) seasonal demands for region-specific processing (i.e. a mosaic change in the size of some brain regions and not others), as certain regions might be of more or less utility depending on season-specific life history, or b) ubiquitous changes in the size of each brain region (i.e. concerted change in brain size; Finlay and Darlington 1995, Striedter 2005). Brain size data were collected in both lakes over six consecutive seasons. Trends in brain size variation were compared to habitat use and movement rates data obtained by acoustic telemetry from one of our study lakes to assess the relationship between seasonal patterns in brain size and behavior. 


\section{Materials and methods}

Study Sites and sample collection

Lake trout were collected seasonally from Lake of Two Rivers (hereafter referred to as "Two Rivers"), Ontario,

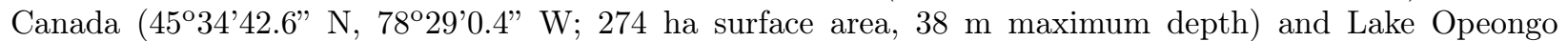

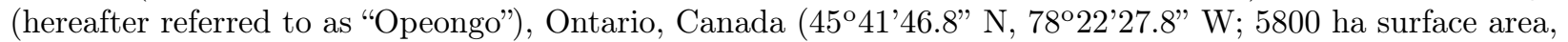
$49.4 \mathrm{~m}$ maximum depth), each located within Algonquin Provincial Park. Unlike Two Rivers, Opeongo supports pelagic prey fish (e.g., lake cisco: Coregonus artedi ). Mature lake trout were sampled seasonally from fall 2017 to winter 2019 (Table 1) using trap nets, gill nets, and angling equipment. The fish were euthanized immediately upon capture via severing of the spinal cord, and their lengths and weights collected (under approved University of Toronto Animal Use Protocols). Fish heads were then removed and placed in labelled containers with $10 \%$ neutral buffered formalin (Fisher Scientific Inc., New Jersey, USA). Fish that possessed undeveloped gonads were considered immature and removed from analysis.

Following previous conventions (Guzzo et al. 2017), the period after ice-off but before mean surface temperature ( $<6 \mathrm{~m}$ depth) exceeded $15 @ \mathrm{C}$ was denoted as spring, summer was defined as the period during which surface temperatures reached or surpassed $15 @ \mathrm{C}$, fall began when lakes cooled to [?] 15@C and lasted until winter, defined as ice-on to ice-off. Water temperatures were measured throughout the upper $6 \mathrm{~m}$ of the water column in each lake using a string of data loggers (HOBO Temp Pro H20-001, Onset, Cape Cod, MA) deployed over the deepest point of each lake (Table 1).

Brain Mass and Region Volumes

Following procedures from Edmunds et al. (2016a), the brains were removed and trimmed of cranial nerves, and the spinal cord was cut at the obex. Each brain was blotted thoroughly to remove excess formalin and was then weighed (resolution of $0.0001 \mathrm{~g}$ ) to obtain brain mass, which was used to estimate brain size. Pictures were taken of the dorsal, left, and ventral sides of the brain using an Olympus SZ61 dissection microscope and a Canon Powershot G9 digital camera and PSREMOTE v1.7 software (Breeze and Breeze 2009). A calibration grid was included in each picture. The height, length, and width of brain regions visible on the resulting images (olfactory bulbs, telencephalon, optic tectum, cerebellum and hypothalamus) were measured using the measuring tool in ImageJ software (Rueden et al. 1997). Regional volumes $\left(\mathrm{mm}^{3}\right)$ were estimated using the ellipsoid formula: $\mathrm{V}=(\mathrm{L} \times \mathrm{W} \times \mathrm{H}) \pi / 6$, providing us with estimates of size for each brain region. Volume measurements were conducted by the same person (EJV) and measurement accuracy was assessed by repeating measurements of five randomly selected brains ten times (Appendix S1: Table $\mathrm{S} 1)$.

\section{Acoustic telemetry}

Acoustic telemetry data were available from Lake of Two Rivers throughout the study period, albeit for a different subset of lake trout individuals $(n=9)$. Fixed location reference tags within the array provided a measure of array performance throughout the study period. Estimated positions based on the Vemco (InnovaSea, WA, USA) positioning algorithm were compared with known positions of the tags to quantify positioning errors across seasons and years using methods proposed in Smith (2013). Reference tags at 5 $\mathrm{m}$ depth had a lower average error than tags placed at $18 \mathrm{~m}$ depth. Over $95 \%$ of detections at $5 \mathrm{~m}$ had a positional error of less than $6 \mathrm{~m}$ vs. $86 \%$ at the $18 \mathrm{~m}$ depth. Overall mean error was $2.41 \mathrm{~m}$ vs $5.24 \mathrm{~m}$ at 5 and $18 \mathrm{~m}$ depth, respectively. Additional details about the telemetry array setup, performance, and fish tagging can be found in (Appendix S2).

\section{Statistical Analysis}

Seasonal differences in lake trout brain mass and each brain region volume were explored using separate linear models (LM's). $\log _{10}$ transformed brain mass or brain region volume was the dependent variable, season, lake and sex were included as fixed factors, and $\log _{10}$ transformed fork length as a covariate (fork length was 
positively linearly related to brain mass and the volume of the individual regions; Appendix S1: Table S2, Figure S1). An alpha of 0.05 was used for all analyses. An interaction between lake and season was included to evaluate if the effect of season on brain size varied between lakes. Preliminary analyses indicated that the main effect of sex and the interaction between sex and season did not significantly influence the models, so sex was removed from the final analysis. Similarly, if the main effect of sex was not a significant parameter for a given model, it was removed. Following a significant main effect of season, seasonal differences were identified using Tukey's pairwise comparisons of estimated marginal means (EMMs). The initial model for brain mass was run including all six seasons spanning our two study years (Table 1). After finding no significant differences between the two fall seasons or the two winter seasons (Figure 2a), these seasons were combined (resulting in 4 seasons: spring, summer, fall, winter) in all subsequent analyses of brain mass and individual brain regions.

Acoustic telemetry data were modelled using generalized additive mixed models (GAMMs; Wood 2011, 2017). After filtering the data (Appendix S3), we performed four separate analyses on: 1) weekly mean depth, 2) standard deviation (SD) of depth, 3) mean distance to shore, and 4) mean horizontal movement rate (Appendix S1: Table S5). We fit two models for each of these response variables. The first model, known as the year-specific smoother model (YS), had separate seasonal smoothers for each year (March 2017 - March 2018 and March 2018 - March 2019) by including a factor-smoother interaction between week of the year and year, with seasonality in behavior represented by week of the year and treated as a cyclic cubic regression spline (knots = weeks 1-52). The second model, known as the common smoother model, contained a single seasonal smoother treated as a cyclic cubic regression spline common to both years of data. In each model we included fish ID as a random effect, and autoregressive and moving average (ARMA) correlation structures were added to the models to account for autocorrelation. The correlation structures used in each model, where $\mathrm{p}$ is the order of the autoregressive (AR) part and $\mathrm{q}$ is the order of the moving average (MA), were $\mathrm{p}=2, \mathrm{q}=1$ for mean depth, SD depth, and mean distance to shore and $\mathrm{p}=2, \mathrm{q}=2$ for movement rate. Once the most appropriate correlation structures were identified for each response variable, we fit the two candidate models using maximum likelihood and ranked them using AIC. The model with the lowest $\mathrm{AIC}$ value was chosen and a difference in $\mathrm{AIC}<2$ meant equal support for both models, in which case the simpler CS model was chosen. We then refit the selected model using restricted maximum likelihood to obtain parameter estimates and significance $(\alpha=0.05)$.

\section{Results}

\section{Hypothesis 1: Brain Size}

When including data for all six seasons sampled across our two study years, Opeongo lake trout relative brain size decreased from fall and winter highs to spring and summer lows before increasing again in the fall and winter of the second study year (Figure 2a). In Two Rivers, larger relative brain size in fall and winter was limited to the second year of sampling (Figure 2a). Season and lake had significant effects on lake trout relative brain size according to the LM, though there was no significant season-lake interaction (Table 2). Fall and winter of the first year did not significantly differ from fall and winter of the second year (Figure 2a, Appendix S1: Table S3), and the data from each of these seasons over two years were combined for subsequent analyses (resulting in 4 seasons).

In the LM performed on the four seasons, season and lake had significant effects on lake trout relative brain size (Table 2). Opeongo trout: a) were larger than Two Rivers trout (mean fork length \pm SD: $510 \pm 54.6$ vs. $410 \pm 40.2 \mathrm{~mm}$; mean body mass \pm SD: $1574 \pm 504$ vs. $775 \pm 228 \mathrm{~g}$ ), b) had a larger mean absolute brain size $(0.832 \pm 0.134 \mathrm{SD}$ vs. $0.692 \pm 0.134 \mathrm{~g})$, but c) had a smaller relative brain size compared to Two Rivers trout (i.e. after correcting for body size; Appendix S1: Table S2, Figure S1). The effect of season on relative brain size did not differ between lakes (season-lake interaction was not significant; Table 2). Tukey's pairwise comparisons of seasonal EMMs demonstrated that relative brain size was smaller during the spring and summer, and larger during the fall and winter when the two study years were combined (Figure $2 \mathrm{~b}$, Appendix S1: Table S3). 


\section{Hypothesis 2: Brain Region Sizes}

Next, we evaluated if changes in brain size were region-specific or if changes involved all regions observable at the gross morphology level. When using a LM with fork length as a covariate to correct for variation in body size, the main effect of lake was significant: fish from Two Rivers had relatively larger telencephala (lake: $\mathrm{F}_{2,134}=250, \mathrm{P}<0.001$ ), cerebella (lake: $\mathrm{F}_{2,134}=260, \mathrm{P}<0.001$ ), optic tecta (lake: $\mathrm{F}_{2,134}=370.6$, $\mathrm{P}>0.001$ ), and olfactory bulbs (lake: $\mathrm{F}_{2,134}=205.4, \mathrm{P}>0.001$ ) than those from Opeongo. There was a significant interaction between fork length and lake for hypothalamus size $\left(\mathrm{F}_{3,133}=109, \mathrm{P}=0.003\right)$, where different allometric slopes produced Two Rivers fish with larger hypothalami than Opeongo fish at smaller fork lengths (Appendix S1: Figure S1).

The main effect of season and lake was also significant for all five brain regions, yet none of the regions demonstrated a significant interaction between season and lake. Thus, the seasonal patterns observed in brain regions were not population-specific (Table 2). Telencephalon size followed a trend similar to that of the whole brain (smaller in spring and summer, larger in fall and winter; Figure 3a), while cerebellum size was smallest during the spring, with no significant differences between the fall, winter, and summer (Figure 3b, Appendix S1: Table S3). Although season was a significant factor in the LM, the optic tecum did not differ between any seasons based on the Tukey tests ( $\mathrm{P}>0.06$; Appendix S1: Table S4), however the general trend in this region was for lower size in the spring (Figure 3c). Like the cerebellum, both the olfactory bulbs and the hypothalamus were smallest during the spring, with no significant difference between summer, fall, and winter (Figure 3d,e, Appendix S1: Table S4).

\section{Acoustic Telemetry}

Model selection indicated that each of the movement and habitat use metrics from Lake of Two Rivers trout were best modelled using a GAMM with a year-specific weekly smoother rather than a common weekly smoother (Appendix S1: Table S4). During the summer, lake trout occupied greater depths ( $\sim 12 \mathrm{~m}$; Figure 4a) and were located well over 300 meters away from shore (Figure $4 \mathrm{~b}$ ). Pronounced vertical movement in the water column were characteristic of summer months (high SD of depth, Figure 4c), while horizontal movements were lowest at this time (Figure 4d). Conversely, lake trout occupied shallower depths during the coolest weeks of the year (fall, winter, early spring: Figure 4a). Rapid depth changes occurred around weeks 20 and 40 (mid-May and early October), with fish moving offshore to deeper water in the late spring (immediately following the Spring sample collected in May) and back nearshore into shallow water in early October (Figure 4a). Fish remained in generally shallow water throughout the winter. These periods of low depth occupancy in the spring, fall, and winter coincided with shorter distances from shore (Figure 4b) and a low SD in depth (Figure 4c), indicating that the fish were not regularly changing position in the water column during that time. Horizontal movement rates were lowest in the summer and increased dramatically in the fall (Figure 4c). Horizontal movement rates were higher in the second compared to the first winter, however this did not seem to be due to differences in system positioning error between winters.

\section{Discussion}

Our data suggest that the brain size of a temperate freshwater fish changes within an annual timespan, mirroring seasonal changes in habitat use and movement. Larger relative brain size in Two Rivers lake trout, which do not have access to an offshore forage fish and as a result forage more frequently in nearshore habitats (Vander Zanden and Rasmussen 1996), is consistent with previous observations that fish species and populations with a higher reliance on the nearshore habitat have larger brains (Edmunds et al. 2016b, Axelrod et al. 2018). Seasonal variation in relative brain size was apparent across both lakes, with brains being smallest during the spring and summer and largest during the fall and winter. It is unlikely that lake temperature alone was responsible for these trends. Though larger brain sizes have been associated with higher temperatures (and possibly metabolism; Gillooly and McCoy 2014, Yu et al. 2014, Závorka et al. 2020), we observed that lake trout brain size was smallest during the warmest season (summer). Previous work has suggested that increases in brain size reflect increased performance in cognitively demanding tasks (Kotrschal et al. 2013, Buechel et al. 2018). Our findings therefore support our first hypothesis that fish alter 
their brain size seasonally, potentially in accordance with seasonal variation in cognitive demands.

Variation in whole brain size reflects underlying variation in individual brain regions, which were also found to vary seasonally. The telencephalon tracked the observed changes in brain size best (larger in the fall and winter compared with spring and summer). Larger telencephala have been associated with higher utilization of nearshore habitats (Gonzalez-Voyer and Kolm 2010, Edmunds et al. 2016a). In their investigations of the round goby Neogobius melanostomus, McCallum et al (2014) also found larger telencephalon sizes prior to the spawning season. As lake trout move nearshore onto spawning shoals in the fall, they navigate more structurally heterogeneous environments, while also coordinating complex social behaviors during mating (Johnson et al. 2018). Nearshore habitat use was maintained throughout the winter (at least in telemetered Two Rivers lake trout), which would also be associated with navigating under reduced light conditions (due to reduced photoperiod and snow and ice cover; Blanchfield et al. 2009). Larger telencephala in the fall and winter could therefore reflect increased cognitive demands associated with spawning in the fall and nearshore habitat use during the fall and winter. Nearshore foraging is also known to occur in spring (Guzzo et al. 2017) however, and telemetered lake trout in our study had just begun to move away from shore at the time of spring sampling. Smaller telencephala in the spring and summer could, therefore, be associated with movement into offshore, deeper water.

Unlike the telencephalon, seasonal changes in size of the other brain regions were limited to a decrease in size in the spring. Nearshore habitat use is higher in fall and winter compared to summer, and reproduction occurs in the fall (Guzzo et al. 2017). Habitat use and spawning alone are likely insufficient to explain the size of these brain regions, which were of similar size in fall, summer, and winter. The smaller size of the cerebellum, olfactory bulb, optic tectum, and hypothalamus in spring vs. fall may potentially be driven by increased lake trout foraging and growth during the spring (Fry 1939, Guzzo et al. 2017). Large increases in total body length during spring months may reduce the relative brain size to body length ratio; such a dilution would be expected if brain growth lags behind patterns in global/systemic growth. Alternatively, reduced brain sizes during the spring may be a product of energy trade-off mechanisms that mediate energetically expensive tissues to optimize growth potential. Trade-offs in brain and gut size, for example, have been observed in fish and other vertebrates (Aiello and Wheeler 1995, Kotrschal et al. 2013, Monnet et al. 2020, Rosenfeld et al. 2020). Investment in large, energetically expensive digestive organs in support of growth in the spring could entail temporary reduction in brain size to allow a more effective allocation of resources to different parts of the organism (Armstrong and Bond 2013). Whether such organ system trade-offs happen on a seasonal scale is unknown. Future work is required to explore how seasonally changing cognitive and energetic demands might govern the size of the brain and its regions.

Previous work has identified seasonal brain size flexibility. The size of the telencephalic hemispheres and whole brain of a benthic fish and a shrew, respectively, have exhibited distinct seasonal patterning (McCallum et al. 2014, Lázaro et al. 2018). Seasonal variation in the size of a specific brain region, the hippocampus, has also been noted in birds and mammals (Yaskin 2011). However, the inability to follow the record brain metrics from the same individuals over time represents a central limitation to our study (and previous studies on this topic), given that, at this time, animals must be sacrificed to measure brain sizes. We therefore cannot discount the possibility that individuals captured during fall and winter tended to be those individuals within the population that had larger brains. We have also included a limited set of ecological traits (i.e., habitat use, movement rates, fall reproduction by using mature individuals), making our inferences about the role of brain size in these behaviors tentative until a larger suite of traits can be explored. Additionally, we echo previous concerns about the uncertain role of brain size in cognition, and stress caution when interpreting its relationship with complex behaviors (Healy and Rowe 2007). However, the fact that we observed the same seasonal trend in both lakes, and the observation that larger relative brain masses coincided with increased nearshore habitat use and movement rates in telemetered Lake of Two Rivers lake trout suggest that brain size of lake trout is seasonally flexible in support of, or in response to, changes in behavior. More work will be needed to elucidate which specific behaviors are impacted by seasonally flexible changes in brain size. 


\section{Conclusions}

Here, we find novel evidence that brain size changes seasonally in two wild populations of a top-predator teleost fish. The whole brain and telencephalon sizes were smaller in spring and summer, while the other brains regions investigated were only smaller in the spring. These distinct seasonal cycles could subserve different functions associated with differential habitat use during cold and warm seasons, and differential energetic allocation of resources between tissues in support of foraging and growth in the spring. Further investigation will be needed to elucidate the mechanisms that drive seasonal variation in brain size and to identify the specific roles that this phenomenon plays in the regulation of fish behavior and physiology.

\section{References}

Armstrong, J. B., and M. H. Bond. 2013. Phenotype flexibility in wild fish: Dolly Varden regulate assimilative capacity to capitalize on annual pulsed subsidies. Journal of Animal Ecology 82:966-975.

Axelrod, C. J., F. Laberge, and B. W. Robinson. 2018. Intraspecific brain size variation between coexisting sunfish ecotypes. Proceedings of the Royal Society B: Biological Sciences 285.

Breeze, C., and S. Breeze. 2009. PSREMOTE. Breeze Systems Limited, Camberley.

Buechel, S. D., A. Boussard, A. Kotrschal, W. van Der Bijl, and N. Kolm. 2018. Brain size affects performance in a reversal-learning test. Proceedings of the Royal Society B: Biological Sciences 285.

Dill, L. M. 1983. Adaptive Flexibility in the Foraging Behavior of Fishes. Canadian Journal of Fisheries and Aquatic Sciences 40:398-408.

Edmunds, N. B., K. S. McCann, and F. Laberge. 2016a. Food Web Structure Shapes the Morphology of Teleost Fish Brains. Brain, Behavior and Evolution 87:128-138.

Edmunds, N. B., F. Laberge, and K. S. McCann. 2016b. A role for brain size and cognition in food webs. Ecology letters 19:948-955.

Finlay, B. L., and R. B. Darlington. 1995. Linked regularities in the development and evolution of mammalian brains. Science 268:1578-1584.

Fong, S., S. D. Buechel, A. Boussard, A. Kotrschal, and N. Kolm. 2019. Plastic changes in brain morphology in relation to learning and environmental enrichment in the guppy ( Poecilia reticulata ). The Journal of Experimental Biology 222:jeb200402.

Fry, F. E. J. 1939. A comparative study of the lake trout fisheries in algonquin park, ontario. Publications of the Ontario Fisheries Reserarch Laboratory 46:1-69.

Gillooly, J. F., and M. W. McCoy. 2014. Brain size varies with temperature in vertebrates. PeerJ 2014:1-8.

Gonda, A., G. Herczeg, and J. Merilä. 2013. Evolutionary ecology of intraspecific brain size variation: a review. Ecology and Evolution 3:2751-2764.

Gonzalez-Voyer, A., and N. Kolm. 2010. Sex, Ecology and the Brain: Evolutionary Correlates of Brain Structure Volumes in Tanganyikan Cichlids. PLoS ONE 5:1-9.

Guzzo, M. M., P. J. Blanchfield, and M. D. Rennie. 2017. Behavioral responses to annual temperature variation alter the dominant energy pathway, growth, and condition of a cold-water predator. Proceedings of the National Academy of Sciences of the United States of America 114:9912-9917.

Hanson, K. C., C. T. Hasler, S. J. Cooke, C. D. Suski, and D. P. Philipp. 2008. Intersexual variation in the seasonal behaviour and depth distribution of a freshwater temperate fish, the largemouth bass. Canadian Journal of Zoology 86:801-811.

Herczeg, G., A. Gonda, G. Balázs, K. Noreikiene, and J. Merilä. 2015. Experimental evidence for sex-specific plasticity in adult brain. Frontiers in Zoology 12:1-7. 
Huber, R., M. J. Van staaden, L. S. Kaufman, and K. F. Liem. 1997. Microhabitat use, trophic patterns, and the evolution of brain structure in african cichlids. Brain, Behavior and Evolution 50:167-182.

Johnson, N. S., D. Higgs, T. R. Binder, J. Ellen Marsden, T. Buchinger, L. Brege, T. Bruning, S. Farha, and C. C. Krueger. 2018. Evidence of sound production by spawning lake trout (Salvelinus namaycush) in lakes huron and champlain. Canadian Journal of Fisheries and Aquatic Sciences 75:429-438.

Kotrschal, A., B. Rogell, A. Bundsen, B. Svensson, S. Zajitschek, I. Brännström, S. Immler, A. A. Maklakov, and N. Kolm. 2013. Artificial selection on relative brain size in the guppy reveals costs and benefits of evolving a larger brain. Current Biology 23:168-171.

Kotrschal, K., M. J. Van staaden, and R. Huber. 1998. Fish brains : evolution and environmental relationships. Reviews in Fish Biology and Fisheries 8:373-408.

Lazaro, J., M. Hertel, C. C. Sherwood, M. Muturi, and D. K. N. Dechmann. 2018. Profound seasonal changes in brain size and architecture in the common shrew. Brain Structure and Function 223:2823-2840.

Marhounova, L., A. Kotrschal, K. Kverkova, N. Kolm, and P. Němec. 2019. Artificial selection on brain size leads to matching changes in overall number of neurons. Evolution 73:2003-2012.

Martin, N. V. 1957. Transactions of the American Fisheries Society Delineation of Sympatric Morphotypes of Lake Trout in Lake Superior. Transactions of the American Fisheries Society 86:231-244.

McCallum, E. S., P. M. Capelle, and S. Balshine. 2014. Seasonal plasticity in telencephalon mass of a benthic fish. Journal of Fish Biology 85:1785-1792.

Park, P. J., I. Chase, and M. A. Bell. 2012. Phenotypic plasticity of the threespine stickleback Gasterosteus aculeatus telencephalon in response to experience in captivity. Current Zoology 58:189-210.

Pollen, A. A., A. P. Dobberfuhl, J. Scace, M. M. Igulu, S. C. P. Renn, C. A. Shumway, and H. A. Hofmann. 2007. Environmental complexity and social organization sculpt the brain in Lake Tanganyikan cichlid fish. Brain, Behavior and Evolution 70:21-39.

Rueden, C., W. Rasband, C. Dietz, B. Northan, M. Hiner, L. Kamentsky, J. Scindelin, A. Grislis, B. Dezonia, G. Harris, A. Fraser, and R. Lentz. 1997. Image J. SciJava.

Shuter, B. J., A. G. Finstad, I. P. Helland, I. Zweimüller, and F. Hölker. 2012. The role of winter phenology in shaping the ecology of freshwater fish and their sensitivities to climate change. Aquatic Sciences 74:637-657.

Smith, F. 2013. Understanding HPE in the VEMCO Positioning System (VPS). Pages 1-31 Understanding HPE in the VEMCO Positioning System (VPS).

Striedter, G. F. 2005. Principles of Brain Evolution. Sinauer Associates.

Turschwell, M. P., and C. R. White. 2016. The effects of laboratory housing and spatial enrichment on brain size and metabolic rate in the eastern mosquitofish, Gambusia holbrooki. Biology Open 5:205-210.

Wood, S. N. 2011. Fast stable restricted maximum likelihood and marginal likelihood estimation of semiparametric generalized linear models. Journal of the Royal Statistical Society. Series B: Statistical Methodology $73: 3-36$.

Wood, S. N. 2017. Generalized additive models: an introduction with R. CRC press.

Yaskin, V. A. 2011. Seasonal changes in hippocampus size and spatial behavior in mammals and birds. Biology Bulletin Reviews 1:279-288.

Yu, Y., J. Karbowski, R. N. S. Sachdev, and J. Feng. 2014. Effect of temperature and glia in brain size enlargement and origin of allometric body-brain size scaling in vertebrates. BMC Evolutionary Biology $14: 1-14$. 
Vander Zanden, M. J., and J. B. Rasmussen. 1996. A Trophic Position Model of Pelagic Food Webs: Impact on Contaminant Bioaccumulation in Lake Trout. Ecological Monographs 66:451-477.

Závorka, L., B. Koeck, T. A. Armstrong, M. Soğanci, A. Crespel, and S. S. Killen. 2020. Reduced exploration capacity despite brain volume increase in warm-acclimated common minnow. The Journal of Experimental Biology 223:jeb223453.

\section{Tables}

Table 1. Sample sizes of lake trout for each season (n) and the corresponding date range within which they were sampled from lakes Opeongo and Two Rivers, Ontario. The mean daily surface water temperature $(<$ $6 \mathrm{~m}$ depth) is provided unless the loggers had been removed due to ice cover.

\begin{tabular}{lllll}
\hline Lake & Season & Sample Period & Temp. @C & $\mathbf{n}$ \\
Opeongo & Fall 2017 & Oct. 17 - Nov. 2 & 12 & 9 \\
& Winter 2018 & March 13-16 & Ice cover & 12 \\
& Spring 2018 & May 11-17 & 4 & 16 \\
& Summer 2018 & Aug. 31 - Sept. 10 & 20 & 22 \\
& Fall 2018 & Oct. 30 - Nov. 2 & 10 & 14 \\
\multirow{5}{*}{ Two Rivers } & Winter 2019 & March 18-21 & Ice cover & 11 \\
& Fall 2017 & Oct. 30 & 11 & 6 \\
& Winter 2018 & March 19-21 & Ice cover & 6 \\
& Spring 2018 & May 8-9 & $4 @$ & 20 \\
& Summer 2018 & Aug. 20-21, Sept. 12-15 & 23,19 & 17 \\
& Fall 2018 & Oct. 30 - Nov. 1 & 6 & 21 \\
& Winter 2019 & March 12-15 & Ice cover & 6 \\
\hline
\end{tabular}

Table 2. Results of linear models exploring the main effects of season, lake, and the season-lake interaction on total brain mass and the volumes of individual regions (telencephalon, cerebellum, optic tectum, olfactory bulb, and hypothalamus). Changes in brain mass were first explored across all 6 continuous seasons (i.e., fall, winter, spring, summer, fall, winter) before combining data into 4 seasons (i.e., fall, winter, spring, summer) for subsequent comparisons of brain mass and regional volumes.

\begin{tabular}{llll}
\hline Variable & Season & Lake & Season*Lake \\
Brain mass (continuous) & $\mathrm{P}<0.001$ & $\mathrm{P}<0.001$ & $\mathrm{P}=0.180$ \\
& $\mathrm{~F}_{5,128}=13.7$ & $\mathrm{~F}_{1,127}=0.86$ & $\mathrm{~F}_{5,120}=1.55$ \\
Brain mass (combined) & $\mathrm{P}=0.003$ & $\mathrm{P}<0.001$ & $\mathrm{P}=0.32$ \\
& $\mathrm{~F}_{3,130}=5.00$ & $\mathrm{~F}_{1,129}=97.73$ & $\mathrm{~F}_{3,127}=1.26$ \\
Telencephalon volume & $\mathrm{P}<0.001$ & $\mathrm{P}<0.001$ & $\mathrm{P}=0.311$ \\
& $\mathrm{~F}_{3,130}=8.80$ & $\mathrm{~F}_{1,129}=17.2$ & $\mathrm{~F}_{3,124}=1.2$ \\
Cerebellum volume & $\mathrm{P}<0.001$ & $\mathrm{P}<0.001$ & $\mathrm{P}=0.850$ \\
& $\mathrm{~F}_{3,130}=10.5$ & $\mathrm{~F}_{1,129}=99.9$ & $\mathrm{~F}_{3,124}=0.27$ \\
Optic tectum volume & $\mathrm{P}=0.017$ & $\mathrm{P}>0.001$ & $\mathrm{P}=0.785$ \\
& $\mathrm{~F}_{3,130}=3.55$ & $\mathrm{~F}_{1,129}=76.1$ & $\mathrm{~F}_{3,124}=0.36$ \\
Olfactory bulb volume & $\mathrm{P}>0.001$ & $\mathrm{P}=0.001$ & $\mathrm{P}=0.619$ \\
& $\mathrm{~F}_{3,130}=6.09$ & $\mathrm{~F}_{1,129}=10.8$ & $\mathrm{~F}_{3,124}=0.600$ \\
Hypothalamus volume & $\mathrm{P}=0.007$ & $\mathrm{P}>0.001$ & $\mathrm{P}=0.715$ \\
& $\mathrm{~F}_{3,130}=4.17$ & $\mathrm{~F}_{1,129}=85.8$ & $\mathrm{~F}_{3,124}=0.45$ \\
\hline
\end{tabular}

Figures 


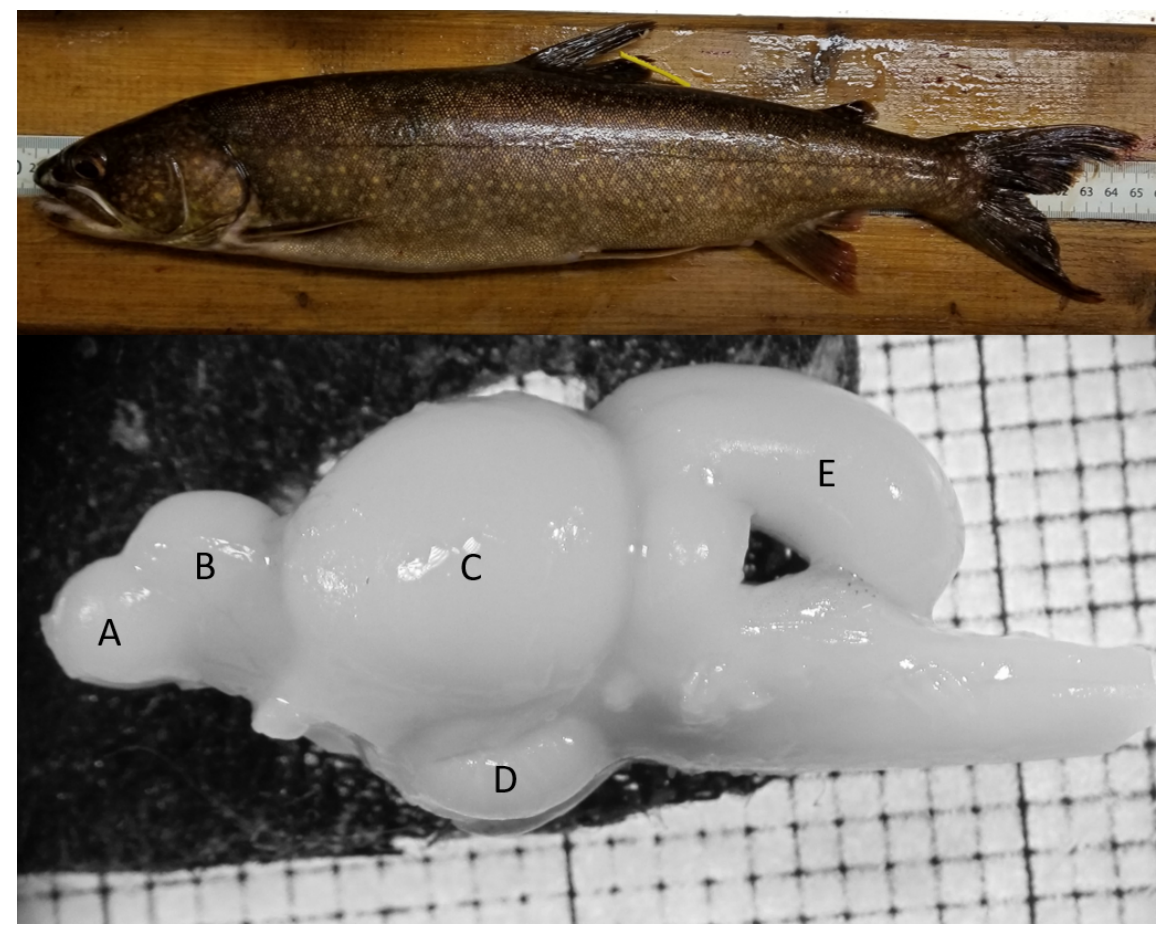

Figure 1. Lake trout (top) and a lake trout brain with letters indicating the regions measured in the present study (bottom). The olfactory bulbs (A) process olfactory information. The telencephalon (B) is primarily associated with spatial navigation and learning. The optic tectum $(\mathrm{C})$ processes visual and multimodal sensory information used for orientation. The cerebellum (D) is associated with motor coordination and learning. The hypothalamus (E) is involved in behavioral and neuroendocrine control (Huber et al. 1997, Pollen et al. 2007). 


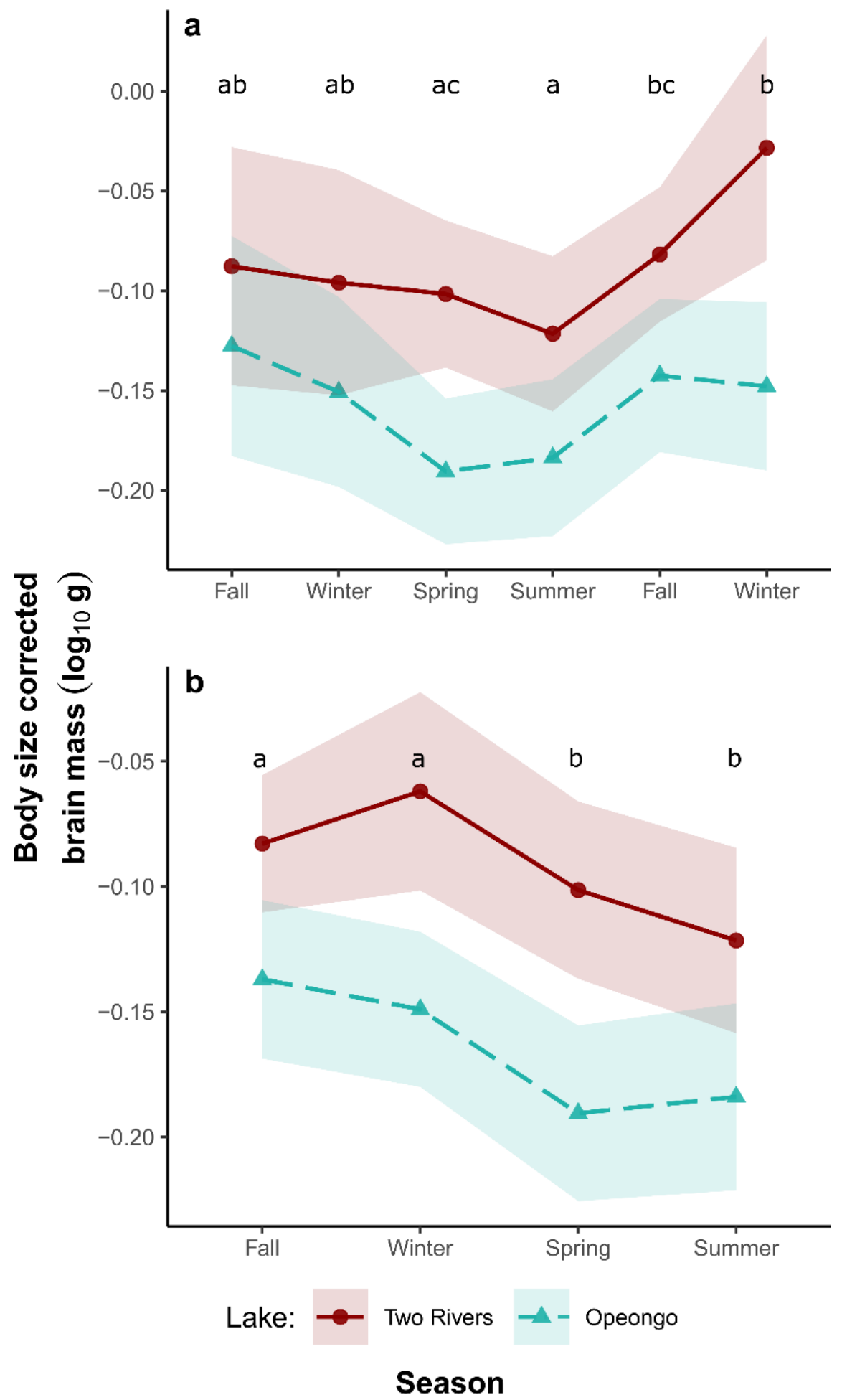

Figure 2. Seasonal variation in relative brain size in lake trout. The curves show estimated marginal means and $95 \%$ confidence intervals (shaded ribbons) of brain mass corrected for fork length in trout from Lake of Two Rivers (red, solid line) and Lake Opeongo (blue, dashed line). A) Model of relative brain size variation 
across six consecutive seasons. B) Model combining two fall and winter sampling seasons. Different letters denote significant seasonal differences $(\mathrm{P}<0.05)$ obtained by Tukey's test.
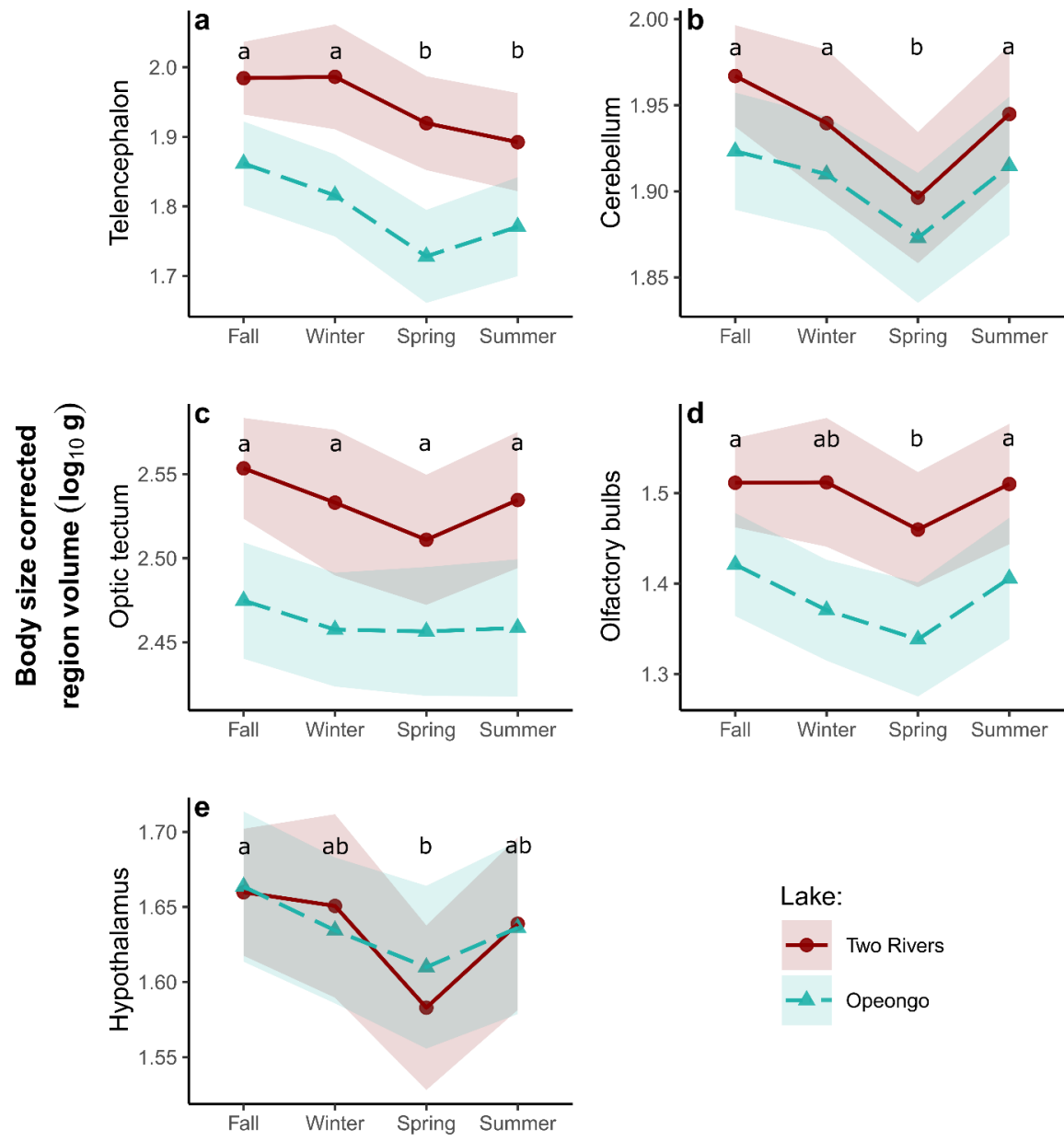

Season

Figure 3. Seasonal variation in relative brain region size in lake trout. The curves show estimated marginal means and $95 \%$ confidence intervals (shaded ribbons) of telencephalon (a), cerebellum (b), optic tectum (c), olfactory bulbs (d), and hypothalamus (e) volumes corrected for fork length in trout of Lake of Two Rivers (red, solid line) and Lake Opeongo (blue, dashed line). Different letters denote significant seasonal differences $(\mathrm{P}<0.05)$ obtained by Tukey's test of models combining two fall and winter sampling seasons. 

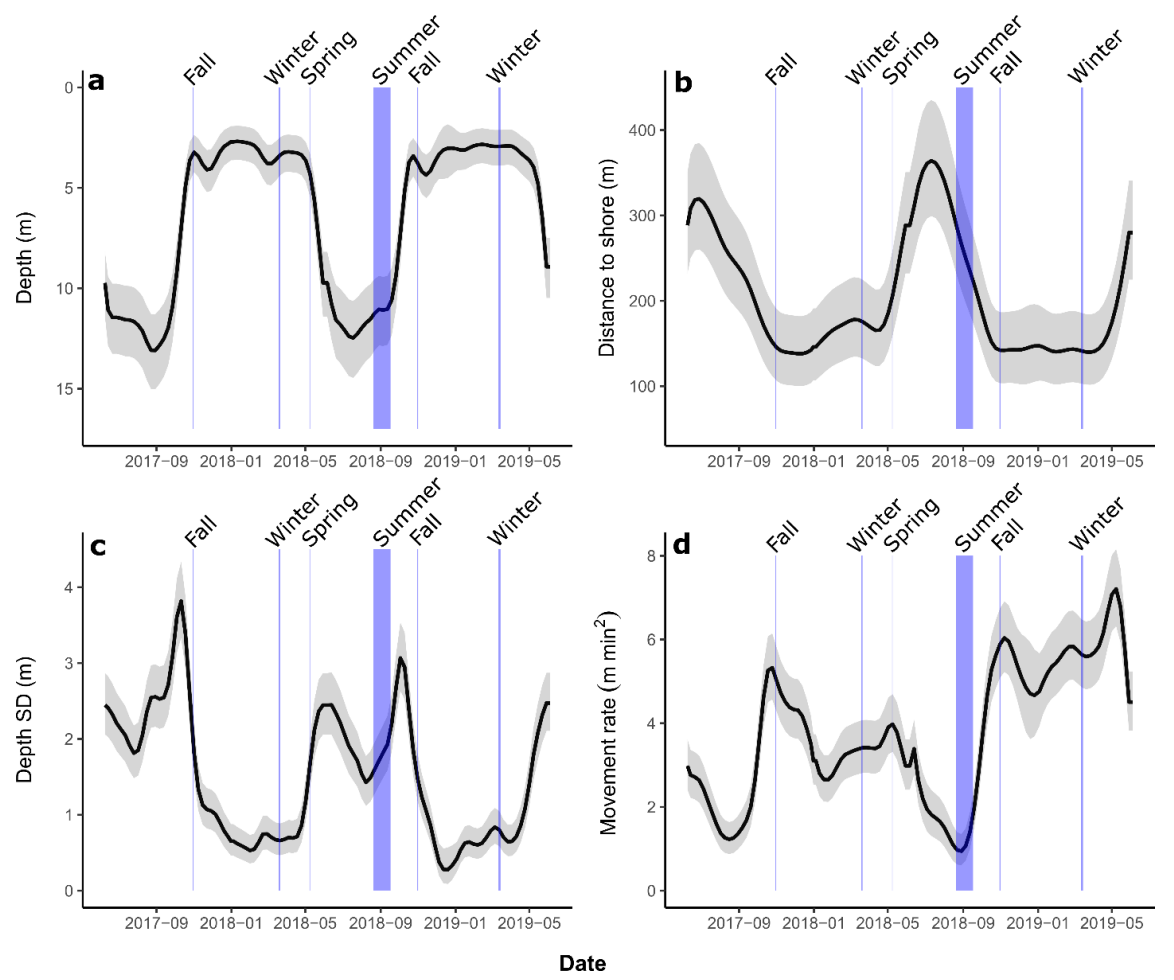

Figure 4. Seasonal variation in lake trout behavior assessed by telemetry. The weekly mean depth (A), distance to shore (B), standard deviation (SD) of depth (i.e., vertical activity; C), and movement rates (D) are shown. The trout were tagged with acoustic tags and tracked using 3D telemetry during June 9, 2017 - June 7, 2019 in Lake of Two Rivers, Ontario. The lines represent mean fits and ribbons are the 95\% CI estimated using generalized additive mixed effects models with year-specific cyclic cubic regression spline smoothers. Vertical lines represent the sampling periods of trout used to measure brain size. The thicker blue line for summer represents a longer sampling period during that season (dates provided in Table 1). 